\title{
TRADUZIR NO SÉCULO XXI ${ }^{1}$
}

Henri Meschonnic

Tradução de: Daiane Neumann ${ }^{1}$

Marie-Hélène Ginette Pascale Paret Passos ${ }^{1}$

${ }_{1}^{1}$ Universidade Federal de Pelotas, Pelotas, Rio Grande do Sul, Brasil

\begin{abstract}
Resumo: Traduzir no século XXI é um texto de Henri Meschonnic no qual ele retoma os eixos de seu pensamento sobre o que é traduzir. O ponto de partida de sua teoria/prática é que traduzir é uma atividade que se inscreve na teoria da linguagem. Portanto, para pensar o traduzir é preciso também pensar a linguagem e sair de uma representação desta presa ao descontínuo do signo que opõe: som e sentido, forma e conteúdo, afeto e conceito, linguagem e vida. Para Meschonnic não pode existir separação entre o vivo e a linguagem. Por isso, ele não pensa a linguagem pelo signo mas pelo ritmo. Um ritmo que ele redefine como a organização do movimento da fala, um movimento contínuo. É na prática de tradução da Bíblia hebraica que Meschonnic embasa a sua reflexão e elabora a sua teoria.
\end{abstract}

Palavras-chave: Henri Meschonnic; Traduzir; Ritmo; Linguagem

\section{TRADUIRE AU XXIE SIÈCLE}

Abstract: Henri Meschonnic's piece of writing entitled "Traduzir no século XXI" readdresses how he conceived of translating. The starting point for his theory/practice is that translating is fully part of the theory of

1 MESCHONNIC, Henri. Traduire au XXIe siècle. Quaderns - Revista de traducción, Barcelona, n. 15, p. 55-62, 2008. Disponível em < http://www.raco. cat/index.php/QuadernsTraduccio/article/download/105019/131312> . Acesso em: 27 out. 2016. 
language. Therefore, reflecting on translating cannot but mean reflecting on language too and opting for a perspective that does not consider the discontinuity of the sign that opposes: sound/meaning, form/content, affect/concept, language/life. According to Meschonnic, life and language cannot be separated. Consequently, language is not considered via the sign, but rather via rhythm - redefined by Meschonnic as an organization of continuous speech movement. Meschonnic based his reflection and his theory on his practical experience of translating the Hebrew Bible.

Keywords: Henri Meschonnic; Translating; Rhythm; Language

A noção de século é uma ilusão do calendário. Os hábitos de pensamento, e em particular o pensamento da linguagem, do que é ou do que faz a literatura não muda de um 31 de dezembro a um $1^{\circ}$ de janeiro. De 2000 a 2001. A teoria e as práticas da tradução fazem parte do pensamento da linguagem.

Nesse sentido, a meu ver, não pode haver uma ciência da tradução, uma tradutologia, autônoma. Senão somente uma maneira, sem dizê-lo ou pensá-lo claramente, uma maneira de se inscrever na hermenêutica, isto é no pensamento do sentido. E de fato é o pensamento do sentido principalmente que conduz, que governa a tradução. Isso aliás parece o bom senso mesmo. Mas o pensamento do sentido é o pensamento do signo.

O que não se vê, é que vivemos em uma representação da linguagem que se dá como a verdade e a natureza da linguagem, não como um ponto de vista. É o que os linguistas chamam de signo: som e sentido, forma e conteúdo, carne e espírito, e finalmente opõe-se assim, na tradição acadêmica, o afeto e o conceito, a linguagem e a vida. Sem saber que se opõe então somente uma representação da linguagem a uma representação da vida, o genérico abstrato das palavras ao concreto individual vivo, biológico.

Ao contrário, eu estabeleço uma inseparabilidade da linguagem e do vivo, mas no sentido em que Spinoza define uma vida humana: não pela circulação do sangue ou pelo que temos em comum com todos os animais, mas pelo que se define pela verdadeira força e vida do espírito, vera Mentis virtute \& vita definitur. 
Mas esse pensamento da linguagem pelo signo, na heterogeneidade entre as categorias da razão, é o que reina há dois mil e quinhentos anos, desde Platão.

E não se vê que dois dualismos se reforçam um ao outro: o dualismo do signo, e o dualismo do ritmo, pois o ritmo também é definido em toda parte metricamente, segundo uma alternância binária de um tempo forte e de um tempo fraco, de um pleno e de um vazio, do mesmo e do diferente. Benveniste mostrou que isso era obra de Platão. Ao contrário de Aristóteles, que dizia que "os metros são partes dos ritmos”, em todos os dicionários das línguas europeias que eu posso ler, o ritmo é definido como uma métrica. Donde a ilusão de que a prosa não tem ritmo.

Contudo traduzir é a prática que melhor mostra como funciona essa representação da linguagem pelo signo, e por isso refletir sobre o que é traduzir supõe inevitavelmente refletir sobre toda a representação da linguagem.

O que mostra o intento maior da teoria do traduzir.

E é o que me parece, em relação ao passado, o futuro do traduzir, a necessidade do bem traduzir, poema do pensamento por poema do pensamento ao mesmo tempo em que a importância maior do traduzir para toda a representação da linguagem.

Então há toda uma transformação a se fazer, e eu não sei se essa transformação acontecerá no século XXI, mas ela deve ser pensada, e programada. Uma mudança é algo que se prepara. É uma estratégia de combate.

Então o intento do traduzir é de transformar toda a teoria da linguagem.

Trata-se de mostrar que o problema maior e mesmo único da tradução é sua teoria da linguagem. Sem sabê-lo, quando se acredita traduzir um texto, é a sua própria representação da linguagem que se mostra, e que se interpõe entre o texto a traduzir e a intenção do tradutor. Ao situar-se no descontínuo do signo linguístico para traduzir um poema, não se traduz o poema, traduzse somente de uma língua para outra língua. Dito de outra forma, não se sabe o que se faz. E não se sabe que não se sabe o que se 
faz. Disso resulta que toda a teoria da linguagem depende de sua teoria da literatura, que toda tradução depende de sua teoria da linguagem, que toda teoria da linguagem depende de sua teoria do ritmo, que o descontínuo depende do contínuo, portanto que toda a teoria da linguagem depende de sua teoria e de sua prática da tradução, assim como a tradução depende de sua teoria da linguagem. O que, imediatamente, mostra o papel maior da tradução para toda a representação da linguagem e da sociedade, assim como toda a sociedade depende de sua representação da linguagem e é revelada por ela. E esse papel não se compara com o de passar mensagens que lhe reserva a representação do signo, que é a representação comum da linguagem. A tradução é portanto o intento de uma verdadeira revolução cultural.

Eu trabalho para transformar toda a teoria da linguagem, isto é toda a relação pensada entre a linguagem, a poesia, a literatura, a arte, a ética, a política, para dela fazer uma poética da sociedade. Isso passa inevitavelmente pelo risco, ou melhor a certeza, de não ser entendido salvo por alguns, dado o estabelecimento de longa data das ideias recebidas, estabelecimento que não concebe essas atividades senão separadas umas das outras, como o mostra o estado do saber, o estado das ciências humanas e da filosofia, o estado da universidade. A teoria da linguagem, ao contrário, é o pensamento do contínuo e da interação entre essas atividades.

Dizem-me que é difícil de entender e que seria preciso escrever para o grande público. Isso é de um desconhecimento profundo do que sempre foi o trabalho do pensamento. O que se chama de grande público nada mais é do que o efeito social de todos os academismos desse estabelecimento, que definem o seu horizonte de expectativa como o território do pensável. O que disso difere e a isso se opõe é ao mesmo tempo o que passa por difícil e logo é rejeitado e silenciado. Nada de novo sob o sol, uma vez que o pensamento é uma loucura que quer mudar o mundo, em relação à manutenção da ordem. Mas é o poema do pensamento.

Não há problema de tradução. Não há intraduzível. Há somente o problema da teoria da linguagem que está em ação no ato de traduzir, 
que se saiba disso ou não. O resultado dessa atividade é um produto que varia em função dessa teoria, de tal forma que toda tradução, antes mesmo de mostrar o que eventualmente resta do que tinha para traduzir, mostra de início a sua representação da linguagem, e sua representação da coisa chamada literatura, ou poesia.

Todo o problema consiste portanto em reconhecer qual representação da linguagem está em ação. É o que está em jogo, segundo o resultado almejado. Segundo se pense a linguagem nos termos do signo, no sentido linguístico, isto é do descontínuo entre significante e significado, nos termos da língua, com a palavra como unidade, e como única atenção a atenção ao sentido, pois o signo não conhece nada além disso. E o paradoxo é que a noção de sentido é um obstáculo epistemológico para pensar a linguagem.

Em particular o signo só conhece o descontínuo, portanto não tem nem conceito nem meio para reconhecer e dar a entender o que existe também na linguagem, e que lhe escapa irremediavelmente, isto é o contínuo, o ritmo, a prosódia, tudo o que é enunciação e significância. Tudo o que faz com que não haja somente o sentido das palavras.

Assim, na medida em que um texto dito literário, mas também um texto filosófico, é essencialmente da ordem do contínuo e inventa o seu pensamento como um sistema de discurso, ver nele somente língua e signo é exatamente o que produz o não-traduzido, donde a noção corrente de intraduzível, noção confusa que mescla elementos antropológicos e elementos poéticos, noção essencialmente determinada pelo signo. O intraduzível é a aplicação do signo sobre o poema. É portanto ao mesmo tempo uma noção teórica e um problema empírico. Mas o empírico aí é o produto da teoria. Ou melhor da carência teórica. E é justamente a ideologia da língua, e unicamente da transferência de língua a língua, tendo como efeito cultural a ideologia do natural, que é ensinada em matéria de tradução.

É dizer imediatamente que não é somente um problema epistemológico. É também, e inextricavelmente, um problema cultural: um problema de história do pensamento da linguagem. 
Por isso seria ingênuo acreditar que sabemos mais hoje, através da linguística formalista do século XX, da história da hermenêutica e da filologia, do que, por exemplo, os Antigos.

Quando vis verbi, vis verborum em Cícero é traduzido pelo dicionário de latim de Freund e pelas edições Belles-Lettres (nas mãos dos melhores especialistas), por "o sentido da palavra, o sentido das palavras", como é o caso, ao passo que a expressão designa: "a força da palavra, a força das palavras", pode-se mensurar o desperdício de sentido da linguagem que caracteriza nossos exegetas. Pois a força é totalmente diferente do sentido. E transborda a pragmática e seu behaviorismo.

Da mesma forma quando, no Peri hermeneias ou De interpretatione de Aristóteles, a tradução canônica de tâ en tê phonê, literalmente "as coisas que estão na voz", é: "as palavras". O que tem imediatamente por consequência que todos esses clássicos deveriam ser retraduzidos.

Mas não porque as traduções envelhecem: é o pensamento da linguagem que envelheceu. E as poucas traduções célebres não envelhecem mais do que as obras. Como a versão King James para a Bíblia, a tradução de Galland para as Mil e uma noites, ou o Fausto de Goethe em Nerval.

Assim a tradução é muito precisamente reveladora da representação de conjunto da linguagem. E seu mau estado tradicional, justamente na medida em que é revelador de uma surdez específica, tem como inverter paradoxalmente o desprezo sociológico e costumeiro de que a tradução é objeto.

Pois a tradução é por isso mesmo o terreno de experimentação das teorias da linguagem. A história das retraduções dos grandes textos mostra plenamente a transformação do olhar e da escuta. Pode-se assim conceber que traduzir é um colocar à prova a teoria da linguagem, e a teoria da literatura.

A tradução, em todos os seus estados, mostra que estamos doentes do signo, e que é toda a nossa representação da linguagem, em suas relações com a literatura, que deve ser mudada. 
A tradução coloca então em jogo a teoria da linguagem inteira e a da literatura. Está ligada a suas histórias. Não se limita a ser o instrumento de comunicação e de informação de uma língua a outra, de uma cultura a outra, tradicionalmente considerada inferior à criação original em literatura. É uma poética experimental. O melhor posto de observação das estratégias de linguagem, pelo exame, para um mesmo texto, das retraduções sucessivas.

O ponto de vista mais antigo sobre a tradução é o ponto de vista empírico e empirista dos tradutores, cujo patrono, emblematicamente, é São Jerônimo, tradutor da Bíblia. É um ponto de vista organizado em função do efeito a ser produzido, no quadro da língua. A tradução é concebida como a passagem de uma língua para uma outra. É analisada em termos de gramática contrastiva (a "estilística comparada") e de estilo individual. Esse ponto de vista funda ainda atualmente o ensino da tradução nas escolas de intérpretes e de tradutores. Parece ter para si a experiência e o bom senso. Seus preceitos maiores são a busca pela fidelidade e pelo apagamento do tradutor diante do texto. Sua transparência deve fazer esquecer que se trata de uma tradução, e visar o natural. No entanto sua força inverte-se em fraqueza diante da constatação do envelhecimento das traduções, em relação à atividade permanente do original, quando se trata de um texto literário que faz parte daqueles que transformam a literatura. Sua fraqueza consiste em ser apenas um pensamento da língua, não um pensamento da literatura. E como a especificidade da literatura lhe escapa, esse ponto de vista não saberia comunicá-la à prática que ele produz.

A hermenêutica alemã no início do século XIX engendrou uma concepção da tradução que a fenomenologia ampliou ao identificar a tradução a uma fenomenologia do compreender, anulando a diferença entre traduzir de uma língua para outra e compreender em uma mesma língua. Tendo, como horizonte, a incompreensão última. O lado Santo Agostino, que seria o patrono do intraduzível. Compreender já seria traduzir, participar de um "traduzir original", - de uma "transferência de nossa essência inteira no domínio de uma verdade transformada" 
(Heidegger). A perífrase e a inserção de glosas na tradução são o efeito direto da doutrina heideggeriana da verdade. Donde os desenvolvimentos de George Steiner em Depois de Babel (1975) que resultam em uma psicologia do tradutor e em uma teologia da incomunicabilidade, em uma mitologia do sentido e da história, ao identificar o semiótico, o intersemiótico e o linguístico. Como o ponto de vista empirista tradicional, a fenomenologia da tradução só conhece o signo, e o etimologismo (a etimologia -origem-essência-verdade). Ela reduz a linguagem à informação no reino do racional e da harmonia universal.

As tentativas de tradução automática desde o final da segunda guerra mundial, no quadro da guerra fria, tiveram um efeito no desenvolvimento de uma linguística da tradução, cujo ecletismo aplicado seguiu o desenvolvimento de diversas doutrinas ao amalgamá-las, da gramática generativa à pragmática contemporânea. $\mathrm{O}$ behaviorismo americano do estímulo/resposta deixou sua marca na teoria e na prática da tradução (no biblista americano Nida). Essa linguística da tradução permanece uma conceptualização da língua, nos termos dualistas do signo: a forma (a "equivalência formal" identificada ao literalismo) e o sentido, a "equivalência dinâmica". A linguística da tradução não busca em absoluto uma teoria de conjunto da linguagem e da literatura.

O último ponto de vista em data é o da poética. É o de um reconhecimento de inseparabilidade entre história e funcionamento, entre linguagem e literatura. E daí o trabalho para reconhecer a historicidade do traduzir, e das traduções. Assim a tradução no mundo ocidental, até o momento em que tratou em primeiro lugar de textos sagrados (a Bíblia) e de um mundo religioso, somente pôde ter como unidade a palavra, e privilegiar, em sua sacralização generalizada da linguagem, a palavra pela palavra. O Renascimento e a tradução dos textos profanos levaram a uma dessacralização da palavra e à passagem à frase como unidade, não sem um desconhecimento do texto como unidade, na prática das "belas infiéis". O romantismo, em seu aspecto filológico de uma busca pelas especificidades, trouxe uma solicitação nova de exatidão. No século XX 
a tradução se transforma. Ela passa pouco a pouco da língua para o discurso, para o texto como unidade. Ela começa a descobrir a oralidade da literatura, não somente no teatro. Ela descobre que uma tradução de um texto literário deve funcionar como um texto literário, por sua prosódia, seu ritmo, sua significância, como uma das formas da individuação, como uma forma-sujeito. O que desloca radicalmente os preceitos de transparência e de fidelidade da teoria tradicional, fazendo-os aparecer como os álibis moralizantes de um desconhecimento cuja caducidade das traduções não é nada senão o justo salário. A equivalência buscada não se coloca mais de língua a língua, tentando fazer esquecer as diferenças linguísticas, culturais, históricas; ela é colocada de texto a texto, trabalhando ao contrário para mostrar a alteridade linguística, cultural, histórica, como uma especificidade e uma historicidade. É a passagem, que está ainda longe de ser compreendida por todos, da anexação para o descentramento, da redução para a identidade em direção ao reconhecimento da alteridade.

É que a tradução não seguiu somente um trajeto em direção a seu próprio reconhecimento. Ela é também solidária da transformação das relações entre as culturas no século XX, ligada às diversas descolonizações e à planetarização dessas relações. Ela passou ou está passando, como essas mesmas relações, de um culto exclusivo de uma identidade tomada como o universal, confusão entre a universalização e o universal, para um sentido novo da alteridade, e da pluralidade. $\mathrm{O}$ encontro das duas transformações maiores desse século - na linguagem, da língua para o discurso; na cultura e no político, da identidade para a alteridade - encontro cujo lugar por excelência é a literatura, faz, apesar das resistências próprias ao estabelecimento dos pontos de vista precedentes no mundo universitário e literário, a condição das mudanças em curso na prática e na teoria da tradução. É também a ética e a política do traduzir.

Pode-se pois considerar como demostrado que o problema maior da tradução é sua teoria da linguagem. O que de início implica duas coisas: a inseparabilidade entre o que se chama de uma teoria e o que se chama de uma prática, ou seja uma prática não é uma prática 
se ela não é reflexiva ou refletida, é somente um balbuciamento de receitas aprendidas, e se ela é essa reflexividade, essa prática implica necessariamente uma teoria de conjunto da linguagem; e reciprocamente uma teoria da tradução que não seria a reflexão de uma prática não passaria de uma linguística da língua aplicada ao discurso, isto é não-pensamento.

Mas, se traduzir sustenta uma teoria da linguagem e é sustentado por ela, traduzir não é mais uma atividade ancilar, tal como ela é tradicionalmente e sociologicamente considerada, traduzir tem um papel maior e único na teoria de conjunto da linguagem: o de uma poética experimental. Porque a história mesma das traduções, ao mesmo tempo a confrontação das traduções sucessivas de um mesmo grande texto, e a observação das estratégias diferentes do traduzir, da evolução das técnicas segundo os tempos e os lugares, toda essa história é o único lugar nas atividades da linguagem, onde há ao mesmo tempo um invariante, o texto a traduzir - a retraduzir - e as variações operadas sobre ele que são as traduções sucessivas, cada uma reveladora primeiro de sua concepção da linguagem, e de sua concepção do objeto literário. A própria literatura não tem essa particularidade: pois tudo o que nela refaz algo é epigonal, logo nato-morto.

Tudo isso, isto é ao mesmo tempo esse papel maior e a explicitação da teoria da linguagem à obra na menor operação de traduzir, só é possível se traduzir empurra para seu ponto de conflito, de ruptura, logo de tomada de consciência e de transformação do fazer, o conflito entre o signo e o poema.

Esse conflito é o do ritmo e do signo. É o do contínuo e do descontínuo, contra o impensado e as ideias recebidas - sobre a linguagem, a língua, o discurso, o objeto literário e poético.

No mundo das ideias como ele está, o que reina é um pensamento da linguagem através da língua, e segundo o dualismo do signo. Do sentido e da forma, dois heterogêneos um ao outro, com passarelas de expressividade. A unidade-palavra. No máximo a frase - última unidade da língua. O discurso somente é visto através do que Saussure chamava de "divisões tradicionais" (léxico, morfologia, sintaxe), isto é os conceitos da língua. 
É esse estabelecimento que a tarefa de traduzir coloca em dificuldade. Mas também o menor poema a traduzir. Pela irredutibilidade do discurso à língua, do contínuo ao descontínuo, que faz estraçalhar a noção tradicional do signo e do ritmo.

A confrontação com outros mundos culturais - onde se situa justamente traduzir - evidencia a não-universalidade das noções comuns do signo e do ritmo, e de uma só vez seu caráter de representações, não de natureza.

A experiência mesma do poema e do traduzir leva a propor que por ritmo não se entenda mais a alternância (binária) tradicional, mas a organização do movimento da fala. O que acarreta uma reação em cadeia, do ponto de vista das representações de toda a linguagem, e que compele a pensar o impensado do empírico.

$\mathrm{O}$ que pode parecer para alguns um desvio por considerações abstratas não faz, ao contrário, nada além de situar o traduzir e aquilo que deve ser traduzido lá onde se passa o que a tradução corrente, que corre tanto ao signo, nem mesmo entende. Logo, não traduz. Ademais, ela nem mesmo sabe que ela não traduz o que ela não ouve.

A tradução segundo o signo - a tradução corrente - é pois o que deveria doravante ser chamada de uma apagadora. Ela apaga o contínuo, o ritmo no sentido do contínuo e ela apaga seu próprio apagamento. O problema poético é de apagar o apagamento das apagadoras.

Não é inútil acrescentar que todo o Ocidente cultural é fundado sobre a tradução de seus textos fundadores (no sentido em que massivamente somente são lidos em tradução, tanto Platão e Aristóteles quanto a Bíblia e o Novo Testamento) e assim o Ocidente se funda sobre o próprio apagamento de suas origens. Gregas e bíblicas.

São justamente esses textos bíblicos que têm um interesse técnico e teórico para o ritmo - muito além de seu papel de "grande código". Pois são conduzidos segundo uma pan-rítmica, que ignora qualquer métrica, logo qualquer oposição entre versos e prosa, e ademais, a antropologia bíblica não conhece a noção de poesia. Unicamente a oposição do falado e do cantado.

Essa pan-rítmica é uma hierarquia de 18 acentos disjuntivos e 9 conjuntivos (12 e 9 para os Salmos, Jó e os Provérbios), com 
três valores: melódico, pausal e semântico. Essa rítmica, única organização do versículo bíblico, foi objeto de uma rejeição teleológico-filológica: sua notação escrita estando tardia. No entanto, o nome de certos acentos designando uma muito antiga queironomia, direção de cantilação por movimentos da mão, necessariamente anterior à sua notação escrita, autentificam sua antiguidade. Por isso o debate teológico-ideológico é resolvido, às custas do teológico -político cristão. Esse era o desafio de um problema, enquanto tal alheio à tradução, mas determinante indiretamente para o estatuto do ritmo, e a sua relação com o traduzir.

O caso o mais patente, e ao mesmo tempo o mais banal (portanto nada próprio à Bíblia) é o do deslocamento de um acento de grupo. Qualquer um sabe que uma vírgula deslocada muda o sentido. O exemplo bíblico o mais marcante é sem dúvida o da voz que fala no deserto, em Isaías $(40,3)$. Mas, no texto, a pausa forte não se passa após "deserto" - é: "Uma voz grita // no deserto / abram o caminho de Adonaï ///2".

Os acentos conjuntivos não têm menos importância, para o afeto, que os acentos disjuntivos. Testemunha, em Gloire (Salmos) 22,2, a sequência: "meu deus meu deus"3", eli éli. Um só grupo, com a subida demarcativa do acento no segundo éli - num sopro só. Nada muda no sentido. No entanto a afeto é mais forte, de um só bocado de linguagem.

Pensar o ritmo como organização do movimento da fala supõe uma gestualidade do sentido, logo uma rítmica ou semântica de posição. Ela é correntemente apagada. Se ela não é traduzida, a tradução perdeu a fala.

Mas o ritmo como contínuo na organização do movimento da fala na escritura não é somente ritmo pausal, ritmo de grupo, ritmo de posição, ritmo de sintaxe, ritmo de repetição, é também o ritmo prosódico, a narrativa do recitativo, não somente a narrativa do sentido das palavras.

\footnotetext{
$2^{2}$ « Une voix crie // dans le désert / ouvrez le chemin d'Adonaï ///».

3 « mon dieu mon dieu».
} 
Assim a teoria da tradução implica o pensamento do ritmo, isto é a conceptualização do contínuo, de uma semântica serial, do semântico sem semiótico, porque ela coloca em jogo o conflito maior e desconhecido entre o signo e o poema, entre o descontínuo e o contínuo. O papel da teoria é de transformar as práticas, o papel das práticas é de expor as teorias. A política da teoria, ao mesmo tempo que a sua necessidade antropológica e poética, portanto a sua faculdade de transformação das práticas é de fazer passar da anexação ao descentramento. É também sua atualidade.

\section{Referências}

MESCHONNIC, Henri. Traduire au XXIè siècle. Quaderns: revista de traducció, n. 15, [S.L.], p. 055-62, 2008.

Recebido em: 14/05/2018

Aceito em: 09/07/2018

Publicado em setembro de 2018

Daiane Neumann. E-mail: daiane_neumann@hotmail.com ORCID: https://orcid.org/0000-0002-7363-0375

Marie-Hélène Ginette Pascale Paret Passos. E-mail: mariehpp@gmail.com ORCID: 0000-0001-7053-0478 